\title{
Coloboma of eye lens
}

INSERM

\section{Source}

INSERM. (1999). Orphanet: an online rare disease and orphan drug data base. Coloboma of eye lens. ORPHA:98943

A rare, genetic, developmental defect of the eye characterized by a uni- or bilateral abnormal lens shape (contraction of the lens with a notch) due to segmentally defective, or absent, development of the zonule and flattening of the equator in the region of the zonular defect, typically manifesting with reduced visual acuity. Other ocular anomalies, such as iris, choroid or optic disc colobomas, as well as cataracts and retinal detachment, may be associated. 